\title{
УДК 811.512
}

UDC 811.512

\author{
Чертыкова Мария Дмитриевна \\ Институт гуманитарных исследований \\ и саяно-алтайской тюркологии \\ Хакасского государственного университета им. Н. Ф. Катанова \\ г. Абакан, Российская Федерация \\ Maria D. Chertykova \\ Institute for Humanitarian Researches and AltaySayan Turkic Studies \\ Katanov State University of Khakassia \\ Abakan, Russian Federation \\ chertikova@yandex.ru
}

\section{СИТУАТИВНО-СТРУКТУРНЫЕ МОДЕЛИ РЕАЛИЗАЦИИ ГЛАГОЛОВ ПАССИВНОГО ВОСПРИЯТИЯ В ХАКАССКОМ ЯЗЫКЕ SITUATIVE-STRUCTURAL MODELS OF VERBS OF PASSIVE PERCEPTION IN THE KHAKAS LANGUAGE}

\begin{abstract}
Аннотация
В рамках семантико-когнитивного подхода рассмотрены глаголы пассивного восприятия в хакасском языке, определены свойственные им ситуативно-структурные модели. Выделено три базовых глагола с залоговыми аффиксами, репрезентирующими пассивное восприятие: кӧрін- 'смотреться; видно'; истіл- 'слышаться; слышно', и чыстан'пахнуть; вонять'. В ходе анализа выявлены специфические семантические особенности данных глаголов, в том числе фиксирующие и активное восприятие. Отмечено шесть пассивных ситуативно-структурных моделей: 1) непосредственное пассивное восприятие окружающей действительности; 2) пассивное восприятие объекта как воспоминание о какой-либо ситуации, событии и явлений; 3) пассивное восприятие объекта как воображение каких-либо ситуаций и явлений; 4) пассивное восприятие объекта как наличие его необходимых характеризующих конкретизаторов; 5) пассивное восприятие объекта через ситуативные / процессуальные факторы, фиксируемые сознанием субъекта; 6) смутное (или неадекватное) восприятие действительности в силу нарушения физического или психического состояния субъекта. Описываемые залоговые формы глаголов могут выражать активное восприятие объекта при описании экстремальных и неожиданных ситуаций. Отрицательное перцептивное суждение в семантике глаголов также нейтрализует пассивное восприятие.
\end{abstract}

\footnotetext{
Abstract

Within the framework of the semantic-cognitive approach, verbs of passive perception in the Khakas language are considered, situational-structural models characteristic for them are determined. It was discovered that 3 basic verbs with the corresponding passive affixes can represent passive perception: кӧрін- 'to look; to be seen'; истіл- 'to be heard', и чыстан- 'to smell; to stink'. The analysis revealed specific semantic features of these passive verbs, including those of active perception. Six situative-structural models were found: 1) direct
} 
passive perception of the reality; 2) passive perception as a memory of a situation, event or phenomenon; 3) passive perception of an object as an imaginative situation or phenomenon; 4) passive perception of an object in the presence of characteristic details; 5) passive perception of an object through situational and process-related factors present in the subject's consciousness; 6) vague (or inadequate) perception of reality due to physiological or psychic violations in the subject. The passive voice forms can also express active perception of an object when they describe extreme or unexpected situations. Negative perceptual judgment in verb semantics neutralizes passive perception as well.

Ключевые слова: хакасский язык, пассивное восприятие, ситуативно-структурная модель, глагол, семантика, субъект.

Keywords: Khakas language, passive perception, situational-structural model, verb, semantics, subject.

doi: 10.22250/2410-7190_2019_5_3_236_247

\section{1. Введение}

В когнитивной модели восприятия фрагментов ситуаций и явлений человеком (и другими живыми существами) выделяются такие классифицирующие признаки, как «активное восприятие» и «неактивное восприятие». Языковая реализация некоторыми базовыми глаголами восприятия данных признаков получает отражение в аспекте их функциональной характеристики и целенаправленности действия.

Категоризация активного и неактивного (или пассивного) восприятия происходит с точки зрения состояния воспринимающего субъекта. Активное восприятие включает такие основные компоненты, как «способность воспринимать», «направленность на объект», «контролируемость ситуации со стороны субъекта». Неактивное же восприятие характеризуется тем, что субъект воспринимает объект, не акцентируя на нём своё внимание. Ю. Д. Апресян называет его «чистым восприятием», «которое происходит само собой, независимо от деятельности других систем. Действительно, можно видеть или сльишать что-л., находясь при этом в совершенно неподвижном состоянии, ничего не желая, не думая, не чувствуя и не говоря» [Апресян, 1995, с. 47]. Таким образом, ситуация неактивного восприятия, в отличие от активного восприятия, характеризуется отсутствием признаков «контролируемость ситуации со стороны субъекта» и «непосредственная направленность на объект», которые заменяются доминированием признака «использование перцептивной способности».

Цель статьи - выявление и описание ситуативно-структурных моделей конструкций, формируемых глаголами неактивного восприятия в хакасском языке.

В хакасском языке пассивное восприятие выражается тремя глаголами, грамматически образованными путём присоединения залоговых показателей: кӧрінерге / кӧрін- / 1) возвр. от кӧрерге 'виднеться, становиться видным, показываться'; кӧрінмес сари 'невидимая сторона'; кӧрінмин па- 
рарва 'скрыться из виду'; кӧрін турарва 'постоянно или время от времени'; $\{\ldots\} ; 2)$ 'выглядеть, казаться'; чахсы кӧрінерге 'хорошо выглядеть'; чиит кӧрінерге 'выглядеть моложаво' [моложе своего возраста]; $\checkmark$ пала кӧрінерге 'родить'; $\square$ айzа, кӱнге кӧрінминче - аваснаң тиң (авас ӧзені) 'загадка ни луне, ни солнцу не показывается, а ростом с дерево (сердцевина дерева)' [ХРС, 2006, с. 207]; истілерге / истіл- / 'слышаться'; ыр истілче 'слышится песня'; чатхан ӥні истілче 'слышатся звуки чатхана'; кӥгӱрт кӥзӥреені истіле тӥскен 'послышались раскаты грома' [ХРС, 2006, с. 138]; иыстанарzа / иыстан- / 'пахнуть, издавать запах, отдавать чем-л.; попахивать'; чыстан парарва 'протухнуть'; тир чыстанча 'пахнет по́том'; ит чы-станча 'мясо припахивает, мясо тухнет'; ниме-де чыстанча 'чем-то пахнет'; чыстан пардан nалых 'протухшая рыба' [ХРС, 2006, с. 1026]. Эти три глагола являются базовыми глаголами восприятия, семантический объём которых осложнён значениями залоговых показателей, что сказывается на структурно-ситуативных способах их реализации. В формируемых ими конструкциях субъект (наблюдатель или говорящий) не выражается грамматически, однако подразумевается его присутствие. «Основой ситуативно-структурного устройства предложения как единицы текста является описание характера взаимозависимости глагольного действия и семантических актантов» [Копров, Козюра, 2006, с. 83].

\section{2. Структурно-ситуативные модели глаголов пассивного восприятия}

В ходе анализа фактологического материала нами выявлены следующие структурно-ситуативные модели реализации хакасских глаголов пассивного (неактивного) восприятия. тельности:

1. Непосредственное пассивное восприятие окружающей действи-

- Ӵс тирек алтында аба іні кӧрінче (Хл, 18) - 'Под тремя тополями видна берлога медведя'.

- Тасхар адайлар пазох ӥрізібіскеннер. Машина кӥӱлеені истілген $(\mathrm{X}, 50)$ - 'На улице опять залаяли собаки. Был слышен гул машины'.

- Аzастар аразында аймах хустар табыстары истілче (Чкч, 279) 'В лесу слышны голоса разных птиц'.

- Тураа толдыра одеколон чыстанча - 'В доме стоит запах одеколона (букв. 'пахнет одеколоном')'.

В подобных предложениях передаётся факт перцепции, осуществляемой за счёт способности субъекта (или агенса) воспринимать. При этом субъект является как бы случайным свидетелем ситуации, происходящей без его ведома и контроля.

2. Пассивное восприятие объекта как воспоминание о какой-либо ситуации, событии или явлении:

- Аның харавына хайди позы даа позынаң кёснең кічіг, хаалавнаң хыссха аңзарныл, хустарны хостачаа пос кӧрінген (Хч, 69) - 'Перед его глазами встала картина (букв. 'в его глаза смотрелось'), как он сам гонял зверей и птиц, уступающих ему в силе и быстроте'. 
- Хулаама пӥ̈н дее аның сӱрдестіг сыылды истілче - 'Мне и сегодня [на ухо] слышится его горькие причитания'.

Модель «восприятие - воспоминание» обычно формируется глаголами кӫрін- 'смотреться; видно' и истіл- 'слышаться; слышно'. Воспоминания о каких-либо обонятельных образах могут быть представлены сложным глаголом, образованным при помощи вспомогательного глагола кил- 'приходить', иыстан кил- 'появляется запах' и выражениями типа чыс сабыл кил- и чыс nypa can кил- с общим значением 'появляется какой-либо запах':

- Пірееде пістің садта ӧсчеткен яблоколар чызы пурныма сабыл килче - 'Иногда мой нос чувствует запах яблок, растущих в нашем саду'.

Обычно в построении таких конструкций участвуют наименования органов восприятия в форме ед. ч. и дат. П.: харахха 'на глаза', хулахха 'на ухо', тунчухха / пурунза 'на нос', уточняющие ситуацию частной (индивидуальной) перцепции: 'видно только мне [моим глазам]', 'слышно только мне [моему уху]', 'пахнет только мне [моему носу]'. При подобном же грамматическом оформлении выражения харахxа кӧрін- букв. 'на глаза смотреться' и хулахxа истіл- букв. 'на ухо слышаться' переходят в разряд фразеологизмов, обозначающих зрительную и слуховую галлюцинации:

- Оолах, харахтарының кӧргеніне киртінмин, «тӥзім полды полар алай ба хараама кӧрінді полар» тіп савын салван (Хч, 172) - 'Мальчик, не поверив своим глазам, подумал, что наверно это была зрительная галлюцинация (букв. '[моим] глазам показалось')'.

- Хулаама табыстар истілче - 'Мне слышатся голоса'.

Тем самым фразеологизмы харахха ниме кӧрін- 'подвергаться воздействию зрительной галлюцинации' и хулахха ниме истіл- 'подвергаться воздействию слуховой галлюцинации' маркированы признаками сильного воздействия на субъекта со стороны мистического объекта.

3. Пассивное восприятие объекта как воображение каких-либо ситуаций и явлений.

- Чоохтаан чоохтар харах алнында кӧрінген осхастар (T, 24) 'Услышанные рассказы так и стояли перед глазами [букв. 'как будто были видны перед глазами']'.

- Чӥреемде ал чӧрген хынызым сарыны саваа истілзін - 'Пусть тебе будет слышна песня любви моего сердца'.

Семантико-когнитивная комбинация «пассивное восприятие - воображение», как и предыдущая модель «пассивное восприятие - воспоминание», относится к уровню абстракции, т.е. к глубинному уровню невербального перцептивного мира. Очевидно, что эти две ноэмические ситуации взаимосвязаны на том основании, что воспоминания - это мыслительная операция в форме воспроизведения прошлого опыта, а воображение - это тоже мыслительная операция, только в форме переработки жизненного опыта. Отличие заключается в разной степени их обусловленности реальной действительностью. В построении модели «пассивное восприятие - воображение» не участвует глагол иыстан- 'вонять; пахнуть'.

4. Пассивное восприятие объекта как наличие его необходимых характеризующих конкретизаторов. Субъект (наблюдатель, говорящий) 
выделяет характеризующий смысловой аспект объекта, учитывающий его признаки и свойства.

- Аннаң ырах нимес орында хайдав-да нимелер азырайып кӧрінчелер (Хч, 188) - 'Недалеко от него видны какие-то торчащие (букв. 'сильно выделяясь') вещи'.

- Чонның аразында хайдав-да сотлос, ніске табыс истіл турван: Сӧле, паза кем коммунисттір (Хч, 32) - 'В толпе был слышен какой-то писклявый голос: - Говори, кто еще коммунист'.

- Ардап парван ит тура толдыра чыстанча - 'Испорченное мясо воняет на весь дом'.

Субъект в воспринимаемой информации выделяет определённые фрагменты (физические свойства объекта), которые оказываются в фокусе его внимания.

В случае ослабления перцептивного признака в семантике глагола кӧрін- 'смотреться; видно', он может синонимизироваться с глаголом пілдір'казаться' и в контекстах они могут взаимозаменяться без ущерба для смыслового содержания предложения, где «... исчезает момент непосредственного восприятия, выражается мнение» [Буглак, 2012, с. 121].

- Аныңң ніскечек мойнычавы, халбах пӧріктіг пазын тіреп сыдабин, хойраларва хынчатхан чіли кӧрінче [пілдірче] (Хч, 6) - 'Казалось (букв. 'видно'), что его тоненькая шейка вот-вот искривится под тяжестью его головы, одетой в пушистую шапку'.

- Анан, сыннаң даа, ибіркі чатхан чирлер айадавы ла чіли кӧрінчелер [nілдірчелер] (Хчк, 209) - 'Да, действительно, окружающие земли смотрятся как на ладони'.

Описание характеристики объекта в таких конструкциях даётся путём употребления послелога с уподобительным значением чіли 'как'.

5. Пассивное восприятие объекта через ситуативные / процессуальные факторы, фиксируемые сознанием субъекта. Данное значение обеспечивается обычно в условиях сочетания с наречиями образа действия: восприниматься хорошо / плохо; чётко / нечётко: хомай кӧрінче 'плохо видно' / хомай кӧрінче 'плохо видно', чарых кӧрінче 'чётко видно' / пӥлес кӧрінче 'смутно видно'; чахсы истілче 'хорошо слышно' / хомай истілче 'плохо слышно'; чарых истілче 'чётко слышно' / пӥлес истілче 'приглушённо слышно'; саличек ле истілче 'слышно чуть-чуть'; хандыра истілче 'слышно очень хорошо'; чахсы чыстанча 'хорошо пахнет' / хомай чыстанча 'плохо пахнет' и так далее.

- Пушкаларнын, пулемёттарның кӥзӥрескені пос истілібіскен (Хч, 188) - 'Грохот от пулемётов и пушек стал слышен чётко'.

Решающими факторами детализации восприятия объекта могут быть следующие: физиологические перцептивные данные субъекта, т. е. порог чувствительности его сенсорных органов; близость / дальность расположения объекта; суточный цикл (темно / светло; недостаточность освещения); наличие / отсутствие физических преград для восприятия и другие.

Также рассматриваемые глаголы описывают ситуацию, акцентируя адвербалии места и времени. 
- Анда-мында тракторлар чарывлааны кӧрінглебіскен паза кӥзеділ чӧрген аттарның пырдырлааннары истілібіскен (Хч, 184) - И там и тут стали видны фонари тракторов и стало слышно ржание коней, пасущихся в ночное время.

- Хончыхтарның сарнасчатханнары иртен иртӧк истілчеткен C самого утра слышно пение соседей.

Дополнительными компонентами предложений, конкретизирующих перцептивные акты, могут быть и обстоятельства, и придаточные предложения образа действия:

- Чоох таң чараанча парван. Анаң олар аарсыбысханнарында, табыс арамнаң, арам истілібіскен (Хч, 186) - 'Разговор шёл до утра. Когда они устали, голоса стали слышны всё реже и реже'.

6. Смутное (или неадекватное) восприятие действительности в силу нарушения физического или психического состояния субъекта.

- Машина килгенін уйzудавы ла чіли піледірбін. Хараам улув чарых теңенін пілчем, кізі табызы ыраххы чирде истілген чіли поладыр (Хл, 103) 'То, что машина пришла, я осознавал, как во сне. Осознавал, как засветили прямо в глаза, и мне казалось, что чей-то голос слышен где-то вдалеке'.

- Адай майывыбысхан. Харахтарына час тартылып, алнында турван тав тумзувы пірде ырах, пірде чавын полып кӧрінген (Хч, 169) 'Собака стала уставать. Глаза стали слезиться. И вершина горы, стоящей перед ним, казалась то далёкой, то близкой'.

- Уйzум аразында час хузух чызы сабыл килгенін сизінгем - 'Сквозь сон [я] почувствовал запах свежего кедрового ореха'.

Семантика глаголов пассивного восприятия представляется в виде своеобразной когнитивной микросистемы, как отражение фрагмента языковой картины мира. Как показывают рассмотренные ситуативно-структурные модели глаголов, одна глагольная залоговая форма может соотноситься с рядом пассивно воспринимаемых ситуаций и событий, имеющих свои специфические особенности.

\section{3. Семантическая структура многозначного глагола кӧрін- 'смотреться; видно'}

Как известно, во всех языках у глаголов зрительного восприятия семантический спектр шире, чем у остальных глаголов восприятия, потому что «именно зрительное восприятие является наиболее активным способом осмысления и понимания мира» [Каксин, 2017, с. 165]. Глагол кӧрін'смотреться; видно', как и исходный глагол кёр- 'смотреть; видеть' может развивать ментальные значения, например, Аның улуг алчаас ит салганы харавына пос кӧрінібіскен (Хч, 180) - 'Стало очевидным (букв. 'стало смотреться свободно') то, что он совершил большую ошибку'.

В сочетании с именем в дат. п. глагол кёрін- реализует значение 'показываться'. В когнитивной модели описываемой ситуации появляется третий участник, к которому смещается фокус перцептивного внимания: Таңда имчее кӧрінерге кирек - 'Завтра надо показаться врачу'. А при реализации значения 'смотреться' в фокусе внимания оказывается сам субъект: 
Ооллар, кӧріндеске дее кӧрінмезе, сіліглер (П, 51) - 'Парни красивы, хоть и не смотрятся в зеркало'. В обоих случаях глагол кӧрін- характеризуется целенаправленностью действия.

Также глагол кӧрін- в функции деепричастия на -in + вспомогательный глагол ал- 'брать' (кӧрініп aл-) является самостоятельной лексемой и имеет специализированное узкое значение 'родить (о животных)' и относится к категории эфвемистической лексики: Кичее, чыbылывдаң, нанзам, торыг хойлагам хулун кӫрініп алтыр (П, 30) - 'Вчера, когда пришёл с собрания, оказывается, [моя] гнедая лошадь родила жеребёнка'.

Таким образом, выделенные нами лексико-семантические варианты семантической структуры глагола кӧрін- подтверждают словарную статью данного глагола в ХРС [ХРС, 2006, с. 207], дополнительная же информация уточняет его эфвемистический оттенок: в сочетании со вспомогательным глаголом ал- 'брать; взять': 'родить' (о животных).

\section{4. Условия нейтрализации пассивного восприятия в семантике глаголов}

Однако в зависимости от контекста описываемые залоговые формы глаголов могут выражать и активное восприятие объекта. При описании экстремальных ситуаций в семантике глагола стирается признак пассивного восприятия и происходит смещение акцента на выделенные её фрагменты.

- Чабызах сынныв, узун пора таарльв, ах пӧріктіг кізічектің хольнда наган сыраңнап кӧрін турван (Хч, 32) - 'Было видно, как низкорослый человечек в белой шапке размахивал наганом'.

- Атыңар!.. Атыңар! - min табыстар истілген (Хч, 32) - 'Стреляйте! Стреляйте! - были слышны голоса'.

- Тасхар команда истілібіскен: Сыххлаңуар! Ниме-нооңарны ныңнахтаныңар (Хчк, 45) - 'На улице послышалась команда: - Выходите! Готовьте свои вещи!'

Особенно заметное акцентирование на активных действиях происходит при употреблении рассматриваемых глаголов в сочетании с вспомога-

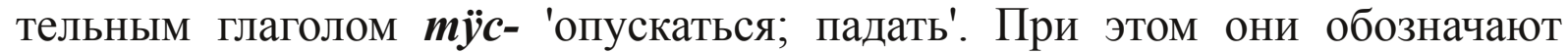

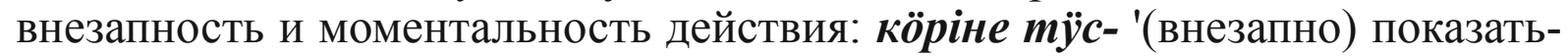

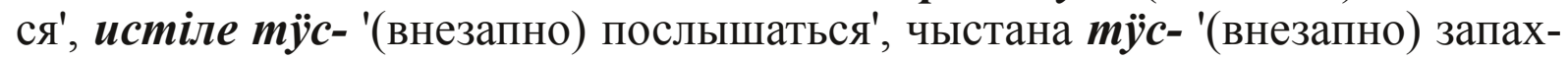
нуть'. Мы предлагаем следующее объяснение данному факту: внезапность, неожиданность действия всегда настораживает человека, что отражается на его психическом состоянии и поведении. Названные глаголы чаще описывают напряжённые ситуации, где объект является психогенным раздражителем, оказывающим деструктивное воздействие на субъекта.

- Сазызылмны даа чахсы хабын полбин одырғанымда, ӧзен пазындавы тыттар аразынаң кізі кӧріне тӥскен (Хл, 101) - 'Я даже не успел прийти в себя, как среди лиственниц, стоящих на вершине лощины показалась голова человека'.

- Ол турада кӧріне тӥссӧк, Тана хайди даа поларын пілбинібісчен (Чкч, 275) - 'Когда он появлялся в доме (букв. 'показывался'), Тана не знала что и делать'. 
- Рома, мині ундубаазың ма? - теен сӧс хулавына истіле тӱскен (Хч, 194) - 'Рома, ты меня не забыл? - внезапно ему на ухо послышались эти слова'.

- Тасхар сыххханыббыста, хайдаz-да чабал чыс чыстана тӱскен 'Когда [мы] вышли на улицу, появился какой-то неприятный запах'.

Как видно из примеров, данные глаголы реализуют доминирующий признак «непроизвольное внимание, привлечённое действием какого-либо раздражителя». В неожиданных (даже экстремальных) ситуациях восприятие объекта может быть кратковременным и моментальным, однако оно может повлиять на дальнейшее психологическое состояние субъекта. Также воспринимаемое субъектом моментальное действие может быть «предвестником» более развёрнутых происходящих событий.

- Am туйzавы тасха тазылаанынаң хада хысхырыс паза тиріг затворын тартханы истіле тӥскен (Хч, 174) - 'Были слышны, как стучали копыта лошади об камни, кто-то крикнул и кто-то дёрнул затвор ружья'.

- Ікӧлең оолахты хыс париван туста «Чохырах!» теен хысхы истіле тӱскен (Хч, 174) - 'В тот момент, когда они вдвоём зажали девушку, послышалось, как кто-то крикнул: «Чохырах!» (кличка собаки)'.

- Суулазыг истіле тӥскен. Оларның хулахтарына таныс табыс читкен (Хч, 176) - 'Послышался шум. До их уха донёсся знакомый голос'.

В конструкциях, формируемых глаголом истіле mӥс- '(внезапно) послышаться', наблюдатель, не контролируя ситуацию, может только обозначать событийные компоненты, доступные его слуховому восприятию.

Значение пассивного восприятия нейтрализуется также в отрицательной форме глаголов кёрін- 'смотреться; видно', истіл- 'слышаться; слышно', иыстан 'пахнуть; вонять'. Отрицательное перцептивное суждение образуется путём присоединения одного из вариантов отрицательного аффикса -ма/-ме; -ба/-бе: кӧрінме- 'не видно', истілбе- 'не слышно', иыстанма- 'не пахнуть'. Соотношение залоговых показателей пассивного восприятия и отрицательных показателей в грамматической структуре данных глаголов обусловлено активностью субъекта восприятия, как производителя действия или носителя состояния. В результате проведённого анализа примеров с данными глаголами, мы можем выделить три характерных признака.

А. Констатация фактов недоступности восприятия объекта.

Субъект, свидетельствуя факт недоступности восприятия объекта, показывает свою отчуждённость от описываемой ситуации.

- Tасхар cымзырых, пір дее ниме истілбинче - 'На улице тишина, ничего не слышно'.

- Тасхар уваa чап-чарых, че кӥн кӧрінминчеткен (Чкч, 279) 'На улице очень светло, но солнца не видно'.

- Тавлар озаринда Мукул чуртапчатхан аал, че ол мыннаң кӧрінмин$\boldsymbol{\varphi}$ (Чкч, 209) - 'За горами деревня, в которой живёт Мукул, но она не видна отсюда'.

- Оларның аразында хыс кізі, сува тастаан тас чіли, кӧрінмин парzан (Хч, 173) - 'Девушка среди них исчезла (букв. не стало видно), как камень, брошенный в воду'. 
Подобные предложения носят исключительно информационный характер, поскольку не маркированы эмоционально-оценочным отношением говорящего к происходящему. Однако в ряде случаев демонстрируется заинтересованное отношение субъекта к отсутствию объекта:

- Син, Айдолай, кӥлерде дее кӥлбе, чоохтап пир, хайдар чӧрдің, ікі кён кізі хараана кӧрінмин? $(П, 5)$ - 'Ты, Айдолай даже и не смейся, лучше расскажи, куда ты ходил, два дня не было видно тебя'.

Б. Недоступность восприятию определённого предмета, явления в силу объективных причин.

При реализации глаголом данного признака имплицируется сема 'переживание субъектом неудобств'. Причинами подобных ситуаций могут служить различные природные обстоятельства и они, как правило, уточняются дополнительными членами или же раскрываются в актуальном смысле предложения.

- Хости даа турван кізі кӧрінминче, харасхы польбыссхан (Хч, 180) 'В темноте стало не видно даже человека, стоящего рядом'.

- Сых килзе - харасхы, соох, хар чаапча. Харахха ниме кӫрінминче (Хч, 187) - 'Вышел - темно, холодно, идёт снег [букв. в глаза] ничего не видно'.

- Пу сувның тӥбі кӧрінминче, че тігі сари кӧрінче, аваа хайди даа чидерге кирек (Чкч, 216) - 'Дна этой реки не видно, но виден другой берег, надо хоть как добираться туда'.

В. Недоступность восприятию желаемого и ожидаемого объекта.

Характерной особенностью реализации данного признака является выражение эмоционального переживания субъектом по поводу недоступности восприятию желаемого и ожидаемого объекта.

- Ибдең сыхсох, автобуста таныс оманы тілеп чӧрче, сынап кӧрінминчетсе, чёреенде кёнзіре пӥрӥнцкі (Хчк, 178) - 'Как только из дома выйдет, в автобусе ищет знакомое лицо. Если его не видно, то на сердце целый день - пасмурно'.

- Прай туган - туустарым ползын пу чараста. Парыңар Порис тайыма, Марин чачам човылох, кумам кӧрінминӧкче $(\mathrm{T}, 6)$ - 'Пусть вся моя родня присутствует на этом перемирии. Идите за дядей Борисом, тёти Марин тоже нет, моей кумы тоже не видно'.

- Хачан истілбинче чонымның чоовы, худылм учухча пурунвы тустарзар $(\mathrm{T}, 72)$ - 'Когда не слышна речь моего народа, мой дух летит к предкам в древние времена'.

Отсутствие желаемого и ожидаемого объекта также обозначается сочетанием пассивно-залоговой основы глагола с отрицательной частицей чогыл, выражающей отсутствие предмета.

- Кирек чохта машиналар аар-пеер ӥзігі чох ӧтісчедедірлер, амды, тізең, нинче дее тыңназам, пір дее ниме истіле чогыл (Хт, 103) - 'Когда не надо, машины снуют туда-сюда, а сейчас, как бы я ни прислушивался, не слышно ничего'.

- Паза даа чапсых-чалаң ниме истіле човыл (Хч, 7) - 'Больше не слышно интересных новостей'. 
- Аның соонаң парзам, Михай от аразында кӧріне човыл (Хл, 95) 'Я пошла за ним, но Михая не видно было в траве'.

Подобные глагольные единицы в тюркских языках именуются предикатами отсутствия. Как показывают примеры, признак «недоступность восприятию желаемого и ожидаемого объекта», реализуемый в семантической структуре исследуемых глаголов, наглядно поддерживается и оттенком «сожаление субъекта о недоступности восприятия объекта».

\section{5. Заключение}

В хакасском языке, по нашим наблюдениям, насчитывается три базовых глагола с залоговыми аффиксами, репрезентирующих пассивное восприятие: кёрін- 'смотреться; видно', (образованный от глагола кёр'смотреть; видеть' при помощи аффикса возвратного залога -ін-); истіл'слышаться; слышно', (образованный от глагола ис- 'слышать' при помощи аффикса страдательного залога -ілл) и иыстан- 'пахнуть; вонять', (образованный путём присоединения к глаголу иыста- 'обонять; нюхать' аффикса возвратного залога -ін-). Ситуативно-структурные модели конструкций, формируемых данными глаголами, представляют когнитивно выделенные фрагменты окружающей действительности, фиксируемые в сознании языковой личности.

В содержательном отношении в семантике исследуемых глаголов выделены дифференциальные признаки, реализующиеся в следующих шести ситуативно-структурных моделях: 1) непосредственное пассивное восприятие окружающей действительности; 2) пассивное восприятие объекта как воспоминание о какой-либо ситуации, событии и явлений; 3) пассивное восприятие объекта как воображение каких-либо ситуаций и явлений; 4) пассивное восприятие объекта как наличие его необходимых характеризующих конкретизаторов; 5) пассивное восприятие объекта через ситуативные / процессуальные факторы, фиксируемые сознанием субъекта; 6) смутное (или неадекватное) восприятие действительности в силу нарушения физического или психического состояния субъекта. Все эти модели обслуживаются выше названными базовыми глаголами пассивного восприятия, только в построении третьей модели «пассивное восприятие - воображение» не участвует глагол иыстан- 'вонять; пахнуть'. Отличительной особенностью субъекта восприятия (наблюдателя, говорящего - в зависимости от контекста) в ситуации неактивного восприятия является то, что он воспринимает, не активизируя своё внимание на объекте, и не прилагая дополнительных усилий, перцепция при этом является неконтролируемой.

Глагол кёрін- 'смотреться; видно', как и исходный глагол кӧр- 'смотреть; видеть', в силу доминирования роли зрительного восприятия в познавательных процессах, является многозначным.

Однако в зависимости от контекста описываемые залоговые формы глаголов могут выражать и активное восприятие объекта, это могут быть описания экстремальных и неожиданных ситуаций. Отрицательное перцептивное суждение в семантике глаголов также нейтрализует пассивное восприятие. 
Таким образом, описанные ситуативно-структурные модели пассивного восприятия объекта отражают разнообразие потенциальных возможностей человека видеть и осмыслять окружающий мир в разных ипостасях и проявлениях.

\section{Список литературы}

1. Апресян, Ю. Д. Образ человека по данным языка: попытка системного описания // Вопросы языкознания. - 1995. - № 1. - С. 37-67.

2. Буглак, С. И. Глаголы сенсорного восприятия в предложении в английском языке // Вестник ЛГУ им. А. С. Пушкина. - 2012. - № 4. - Т. 1 : Филология. C. $120-127$.

3. Каксин, А. Д. Глагольное выражение семантики восприятия в казымском диалекте хантыйского языка // Филология и человек. Научный журнал. - 2017. № 3. - C. 163-171.

4. Копров, В. Ю. О некоторых особенностях выражения субъектно-объектных отношений предложениями с глаголами восприятия и умственного действия в русском и французском языках [Текст] / В. Ю. Копров, Т. Н. Козюра // Актуальные вопросы современной филологии и журналистики. - 2006. - № 1 (1). - С. 83-89.

5. ХРС - Хакасско-русский словарь [Текст] / О. П. Анжиганова, Н. А. Баскаков, М. И. Боргояков, А. И. Инкижекова-Грекул, Д. Ф. Патачакова, О. В. Субракова, П. Е. Белоглазов, З. Е. Каскаракова, А. С. Кызласов, Р. Д. Сунчугашев, М. Д. Чертыкова. - Новосибирск : Наука, 2006. - 1114 с.

\section{Список текстовых источников}

1. Хл - Кирбижекова, У. Н., Коков, И. Ф. Хакас литературазы : 4 класс [Текст] / У. Н. Кирбижекова, И. Ф. Коков. - Абакан, 1977. - 140 с.

2. П - Пьесалар : сборник пьес [Текст] / М. Е. Кильчичаков, В. Г. Шулбаева, Митхас Туран, Г. Г. Котожеков. - Абакан : Хак. издат., 1991. - 264 с.

3. Х - Тюкпиеков, Н. Хыстағда [Текст] / Н. Тюкпиеков. - Абакан : Хак. отд-е Красноярского кн. изд-ва, 1977. - 109 с.

4. Чкч - Чарых кӱнніг чирім. Солнечный мой край : сб. художественных произведений хакасских авторов [Текст] / сост. А. Е. Султреков, Л. В. Челтыгмашева, Н. С. Майнагашева. Абакан : Хак. кн. Изд-во, 2007. - 348 с.

5. Хч - Хызыл чазы. Чоохтар, стихтар, пьесалар [Текст] / В. Кобяков, А. Топанов, М. Коков, А. Кузугашев. - Абакан : Хакасское отд-е Красноярского книжного изд-ва. 1982. - 277 с.

6. Хч - Кобяков В. Хызыл чазы. Красная степь (на хакасском языке) [Текст] / В. Кобяков, А. Топанов. - Абакан : Хакасское отд-е Красноярского книжного изд-ва, 1982. - 277 с.

7. Хчк - Хакас чирінің кізілері. Очерктер. Люди земли хакасской. Очерки (на хакасском языке) [Текст]. - Абакан : Хакасское отд-е Красноярского книжного изд-ва, 1985. - $238 \mathrm{c}$.

8. Т - Казачинова, Г. Той. Повесть паза чоохтар [Текст] / Г. Казачинова, А. Халларов. - Абакан : Хакасское отд-е Красноярского книжного издательства, 1979. $157 \mathrm{c}$. 


\section{References}

1. Apresyan, Yu. D. (1995). Obraz cheloveka po dannym yazyka: popytka sistemnogo opisaniya [The image of man: an experiment in systemic description based on linguistic data]. Voprosy yazykoznaniya [Topics in the Study of Language], 1, 37-67.

2. Buglak, S. I. (2012). Glagoly sensornogo vospriyatiya v predlozhenii v angliyskom yazyke [Verbs of Sense Perception in English Sentence]. Vestnik Leningr. gos. un-ta im. A. S. Pushkina [Vestnik of Pushkin Leningrad State University], 4 (Vol. 1 : Filologiya [Philology]), 120-127.

3. Kaksin, A. D. (2017). Glagol'noe vyrazhenie semantiki vospriyatiya v kazymskom dialekte hantyyskogo yazyka [Verbal Expression of Semantics of Perception in the Kazym Dialect of the Khanty Language]. Filologiya $i$ chelovek [Philolgy and a Human], 3, 163-171.

4. Koprov, V. Yu., Kozyura, T. N. (2006). O nekotorykh osobennostyakh vyrazheniya sub"ektno-ob"ektnykh otnosheniy predlozheniyami s glagolami vospriyatiya i umstvennogo deystviya $v$ russkom i frantsuzskom yazykakh [About some specific ways of expressing subject-object relations by sentences with the verbs of perception and mental processes in Russian and French]. Aktual'nye voprosy sovremennoy filologii $i$ zhurnalistiki [Actual Issues of Modern Philology and Journalism], 1 (1), 83-89.

5. HRS - Anzhiganova, O. P., Baskakov, N. A., Borgoyakov, M. I., InkizhekovaGrekul, A. I., Patachakova, D. F., Subrakova, O. V., Beloglazov, P. E., Kaskarakova, Z. E., Kyzlasov, A. S., Sunchugashev, R. D., Chertykova, M. D. (2006). Khakassko-russkiy slovar' [Khakas-Russian Dictionary]. Novosibirsk : Nauka Press.

\section{Texts for analysis}

1. Hl - Kirbizhekova, U. N., Kokov, I. F. (1977). Khakas literaturazy [The literature of Khakassia] : For the 4th grade. Abakan.

2. P - Kil'chichakov, M. E., Shulbaeva, V. G., Turan, Mitkhas, Kotozhekov, G. G. (1991). P'esalar [Plays] : A collection of plays. Abakan : Khakassia Press.

3. H - Tyukpiekov, N. (1977). Hystazda. Abakan : Krasnoyarskoe Publishing House, Khakas Department.

4. Chkch - Sultrekov, A. E., Cheltygmasheva, L. V., Maynagasheva, N. S. (compilers) (2007). Charyh kÿnnig chirim [My sunny land]. A collection fiction works by Khakas authors. Abakan : Publishing House of Khakassia.

5. Hch - Kobyakov, V., Topanov, A., Kokov, M., Kuzugashev, A. (1982). Hyzyl chazy. Choohtar, stihtar, p'esalar. Abakan : Krasnoyarskoe Publishing House, Khakas Department.

6. Hch - Kobyakov, V., Topanov, A. (1982). Hyzyl chazy. Krasnaya step' [Red prairie] (In Khakas). Abakan : Krasnoyarskoe Publishing House, Khakas Department.

7. Hchk - Hakas chiriniң kizileri. Ocherkter. (1985). [The people of Khakassia]. Essays (In Khakas). Abakan : Krasnoyarskoe Publishing House, Khakas Department.

8. T - Kazachinova, G., Hallarov, A. (1979). Toy. Povest' paza choohtar. Abakan : Krasnoyarskoe Publishing House, Khakas Department. 